\title{
Procedimentos E RECURSOS DE ENSINO PARA O ALUNO COM DEFICIÊNCIA: O QUE TEM SIDO DISSEMINADO NOS TRABALHOS DO GT 15 DA ANPED SOBRE ESTES TEMAS?
}

TEACHING PROCEDURES AND RESOURCES FOR STUDENTS WITH DISABILITIES: WHAT HAS BEEN PRESENTED BY ANPED SPECIAL EDUCATION WORK GROUP ON THESE SUBJECTS?

\author{
Leila Regina d'Oliveira de Paula NUNES ${ }^{1}$ \\ Patrícia BRAUN ${ }^{2}$ \\ Cátia Crivelenti de Figueiredo WALTER ${ }^{3}$
}

\begin{abstract}
RESUMO: o artigo teve o propósito de analisar os 37 trabalhos que versaram sobre procedimentos e recursos de ensino destinados a alunos com deficiência apresentados no GT 15 de Educação Especial da ANPEd, entre 1996 e 2010. Esses artigos representam 17\% do total de 216 trabalhos apresentados nessas 15 reuniões anuais do GT. A perspectiva sociohistórica de Vigotsky fundamentou teoricamente a maioria dos estudos, sobretudos aqueles dedicados à educação de surdos. A população alvo mais estudada foi a de alunos com deficiência intelectual, seguida da surdez, sobretudo no período de 1996 a 2000; estudos dedicados a outras deficiências - física, visual e múltipla - foram menos frequentes. Os estudos descritivos, privilegiando dados qualitativos, envolvendo estudos de caso e etnográficos constituíram a maioria dos trabalhos. Os trabalhos experimentais englobaram delineamentos de grupo e delineamentos intrassujeito. Os estudos foram eloquentes em mostrar a necessidade de o professor observar mais o processo de aprendizagem do que o produto da mesma e a enfatizar o papel essencial da mediação. O processo de desenvolvimento do aluno com deficiência não ocorre da mesma forma que do aluno sem deficiência, não pela condição de deficiência exatamente, mas porque o olhar do outro nem sempre lhe confere a possibilidade para aprender e se desenvolver.
\end{abstract}

PALAVRAS-CHAVE: Procedimentos de ensino. Recursos de Ensino. Aluno com deficiência. Análise de artigos. ANPEd.

\begin{abstract}
The purpose of this paper was to analyze 37 papers regarding teaching procedures and resources designed for students with special needs presented at ANPEd Special Education Work Group, during the 19962000 period. These articles represent $17 \%$ of the 216 papers presented in the last 15 annual ANPEd meetings. Vygotsky social historical perspective served as the theoretical basis for the majority of the studies, especially those concerning education for the deaf. Students with intellectual disabilities were the target population of most studies, followed by students with deafness, mainly during the 1996-2000 period; papers about physical, visual and multiple disabilities were less frequent. Descriptive studies, focusing on qualitative data, involving both case and ethnographic investigations constitute the majority of the articles. Experimental studies included group design as well as single subject designs. The articles were eloquent in both showing the need for teachers to pay more attention to the learning process than to the product of learning and in emphasizing the critical role of mediation. The development process of students with disabilities does not occur in the same way as their typically developing peers. This occurs mainly because of the lack of learning opportunities given to students with special needs, rather than the disabling condition.
\end{abstract}

KEYWORDS: Teaching Procedures. Teaching Resources. Students with Disabilities. Paper analysis. National Association of Post-Graduation and Research.

\footnotetext{
${ }^{1}$ Universidade do Estado do Rio de Janeiro - leilareginanunes@terra.com.br

${ }^{2}$ Universidade do Estado do Rio de Janeiro - p.braun@terra.com.br

${ }^{3}$ Universidade do Estado do Rio de Janeiro - catiawalter@yahoo.com.br
} 
NUNES, L. R. O. P.; BRAUN, P.; WALTER, C. C. F.

Neste artigo, que integra a edição da Revista Brasileira de Educação Especial comemorativa dos 20 anos do GT de Educação Especial da ANPEd, pretendemos mapear e analisar os trabalhos que versaram sobre procedimentos e recursos de ensino destinados a alunos com deficiência apresentados no referido GT, o qual foi criado na $14^{\text {a }}$ reunião anual de 1991. Recuperamos os artigos apresentados entre 1996 e 1999 no CD-ROM Histórico da ANPEd, elaborado em 2002 para celebrar a $25^{\text {a }}$ reunião anual, e aqueles apresentados entre 2000 e 2010 no site da ANPEd. Infelizmente não tivemos acesso aos 59 trabalhos apresentados entre 1991 e $1995^{4}$. O material aqui analisado compreende 37 trabalhos apresentados entre 1996 e 2010 que versaram especificamente sobre processos de aprendizagem, técnicas de manejo de classe, interação professor-aluno, procedimentos, estratégias e recursos de ensino empregados na educação do aluno com deficiência. Esses artigos representam 17\% do total de 216 artigos apresentados nessas 15 reuniões anuais do GT.

A Figura 1 exibe a distribuição dos trabalhos sobre ensino apresentados entre 1996 e 2010.

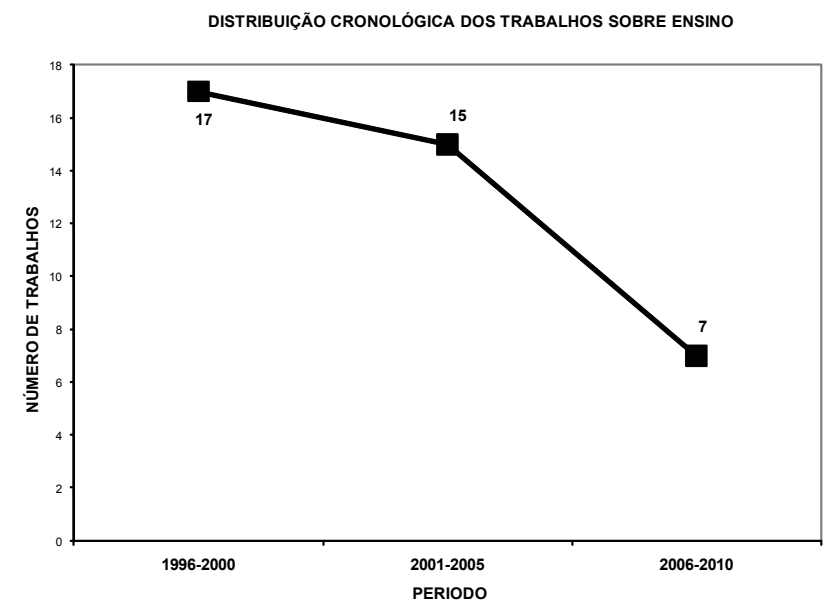

Figura 1 - Distribuição dos trabalhos sobre ensino

O gráfico revela uma nítida tendência decrescente de estudos sobre ensino no período compreendido entre 1996 a 2010.

A população alvo desses estudos está apresentada na Figura 2.

\footnotetext{
${ }^{4}$ Em 1996, na 19a Reunião anual, Julio Ferreira apresentou uma análise da produção do GT Educação Especial do período 1991-1996.
} 


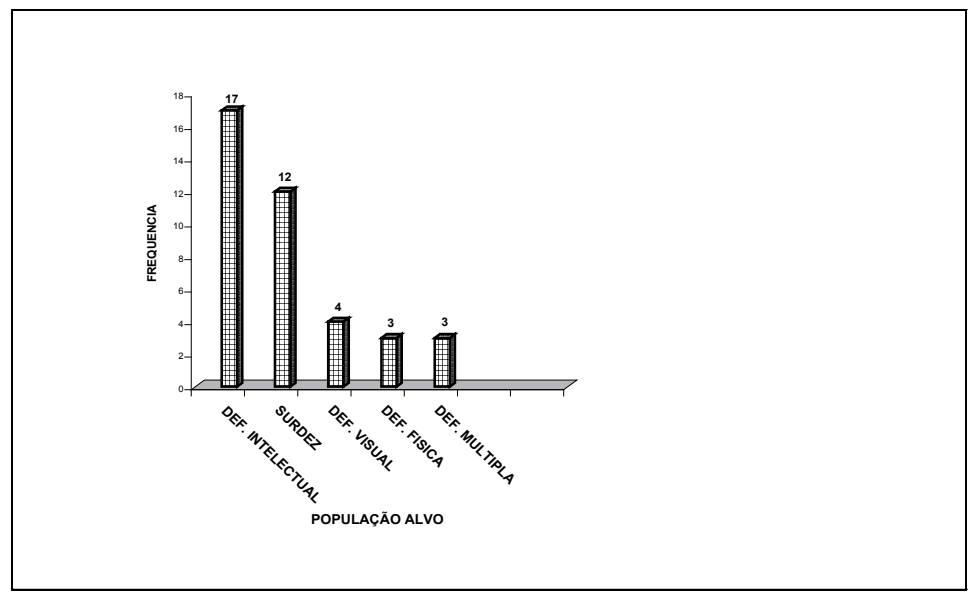

Figura 2 - Número de trabalhos dedicados a cada população alvo

Dentre os 37 trabalhos analisados com reflexões dirigidas para o fazer pedagógico na escola, a deficiência intelectual se destaca com significativa presença. Em seguida, é a surdez o tema mais explorado; estudos dedicados a outras deficiências são menos frequentes. Esta presença privilegiada do aluno com deficiência intelectual como foco teses e dissertações defendidas nos Programas de Pós-Graduação de Educação e Psicologia entre 1981 e 1999, revelou que 34\% do acervo estava comprometida com esta condição especial.

A distribuição cronológica dos estudos, segundo a população alvo, está apresentada na Figura 3.

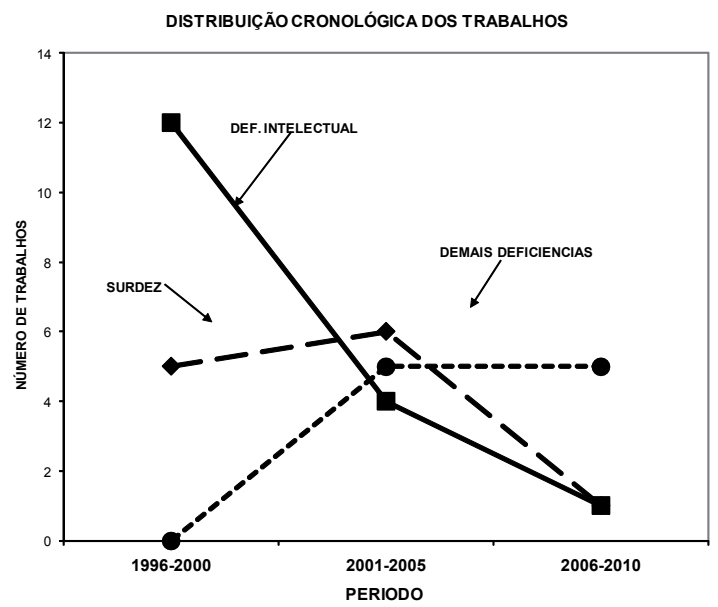

Figura 3 - Distribuição cronológica dos estudos, segundo a população alvo 
NUNES, L. R. O. P.; BRAUN, P.; WALTER, C. C. F.

Os estudos sobre deficiência intelectual e surdez, muito frequentes no período de 1996-2000, decaem nos demais períodos, enquanto o total dos trabalhos sobre as demais deficiências - visual, física e múltipla - exibe leve tendência ascendente.

Uma análise sobre a metodologia de pesquisa dos estudos revistos mostra a distribuição exibida na Figura 4.

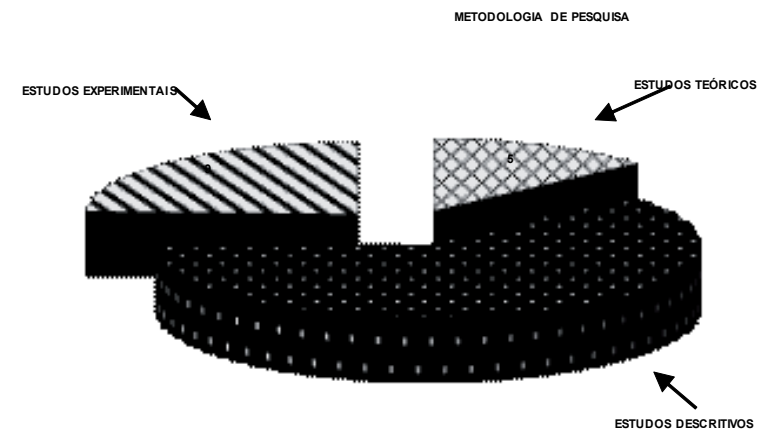

Figura 4 - Metodologia de pesquisa dos estudos revistos

Os estudos descritivos, em sua grande maioria privilegiando dados qualitativos, envolvendo estudos de caso e etnográficos constituíram a maioria dos trabalhos. Os estudos experimentais, com ênfase em dados quantitativos, englobaram delineamento de grupo (5) e delineamento intrasujeito (4).

Trataremos a seguir das análises e reflexões feitas acerca do acervo dedicado a cada uma das populações-alvo.

\section{TrabalHos SOBRE ALUNOS COM DEFICIÊNCIA INTELECTUAL}

Como foi mostrado nos gráficos, estudos sobre procedimentos e recursos de ensino para alunos com deficiência intelectual tiveram maior ênfase na segunda metade da década de 90. A partir dos anos 2000, esta população e as reflexões sobre os temas arrolados estiveram ainda presentes em alguns estudos, porém, com menor destaque. Entendemos que a difusão maior de trabalhos, na década de 90, esteja relacionada principalmente às discussões geradas pela promulgação de documentos internacionais como o da Declaração de Salamanca (1994), considerada um marco a cerca da escolarização de alunos com necessidades educacionais especiais. A partir dessa data, houve um avanço nas políticas públicas para este alunado, no qual estão incluídos aqueles com deficiência intelectual.

Os estudos conduzidos em sala de aula apontam como focos de interesse, com frequência, as interações sociais do aluno na turma e a natureza dos conteúdos, das metodologias e dos recursos de ensino. O estudo de Jesus (1996) é um dos 
primeiros que apontam para essas questões tratadas igualmente por autores como Monteiro (1996), Silva (1997, 1998, 1999, 2000), Padilha (1999), Miranda (1999), Costa (1999), Ribeiro (1999), Victor (2001), Lunardi (2005) e Ferri e Hostins (2006).

Como aporte teórico, observa-se o predomínio da abordagem sociohistórica. Uma comparação da teoria sociohistórica com a teoria piagetiana diante dos processos de aprendizagem do aluno com deficiência intelectual foi privilegiada nos estudos de Silva $(1997,1998)$. Bakhtin e Vigotsky são referendados quando os autores investigam estratégias de ensino para o desenvolvimento e a aprendizagem, tendo como pano de fundo, ou em algum momento do estudo, a linguagem (MONTEIRO, 1996; PADILHA, 1999; MIRANDA, 1999). Alencar (2002) conjugou contribuições do ensino incidental, assentado no que Warren (1988) denominou de soft behaviorism ${ }^{5}$ com algumas premissas da teoria vygotskiana, como mediação e zona do desenvolvimento proximal para favorecer a linguagem e a comunicação de alunos com deficiência intelectual e outros com deficiência múltipla (deficiência intelectual associada à deficiência física, ou ao autismo) sem fala articulada através do emprego dos recursos da comunicação alternativa (cartões com figuras, fotos, símbolos).

A teoria piagetiana fundamentou o trabalho de Costa (1999) que priorizou o atendimento individualizado e as formas de avaliação da aquisição de habilidades de classificação de objetos segundo diversos critérios e serviu igualmente de esteio, ao lado dos estudos de Ferreiro e Teberosky (1986), às investigações sobre os processos de aquisição de leitura e escrita (BONETI,1997, 1999; GOMES; FIGUEIREDO, 2003).

Vale ainda informar que os quatorze estudos empíricos tiveram como campos de observação as escolas/classes regulares e especiais, a sala de recursos e os laboratórios de ensino. Estudos desenvolvidos simultaneamente em escolas/ classes regulares e escolas/classes especiais foram conduzidos por Boneti (1997), Boneti, (1999), Alencar (2002), Gomes e Figueiredo (2003) e Ferri e Hostins (2006). As pesquisas de Monteiro (1996), Miranda (1999), Silva (2000) e Vitor (2001) foram desenvolvidas apenas em escolas/classes especiais; as de Jesus (1996), Ribeiro e Nunes (1999) e Lunardi (2005) ocorreram somente em espaços regulares e finalmente as de Padilha (1999) e Costa (1999) em laboratórios de ensino.

Com a discussão em pauta sobre a inclusão escolar de alunos com deficiência e a crescente promulgação de leis e diretrizes nacionais em prol da educação inclusiva, observa-se uma consonância das investigações com as políticas públicas. Assim, as discussões sobre políticas públicas e aspectos legais da inclusão passaram a comparecer maciçamente no palco das reuniões do GT 15 da ANPEd. Acreditamos, no entanto, que, além de analisar, debater e organizar o arcabouço de aparatos legais para favorecer o acesso do aluno à escola comum,

\footnotetext{
${ }^{5} \mathrm{O}$ soft behaviorism representa uma síntese de cinco abordagens: teoria da comunicação de Bateson et al (1961), teoria do desenvolvimento infantil da linguagem de Bretherton et al (1979), estudos sobre pragmática da linguagem de Bruner (1978), analise experimental do comportamento (SKINNER, 1957) e teoria geral dos sistemas (VON BERTALANFFY, 1950).
} 
NUNES, L. R. O. P.; BRAUN, P.; WALTER, C. C. F.

faz-se mister que a pesquisa se dedique igualmente aos processos de ensino e aprendizagem dos alunos com deficiência. Contraditoriamente, contudo, o micro-espaço da sala de aula, que as políticas se propõem a organizar, e onde o alunado com deficiência passou a ter maior acesso, ficou, de certa forma, relegado a segundo plano na agenda dos pesquisadores que comparecem às reuniões da ANPEd. Assim, os estudos sobre procedimentos e recursos de ensino foram se tornando gradativamente menos frequentes ao longo desta década, como pode ser visualizado no gráfico da Figura 1.

Essa constatação da escassez de trabalhos sobre processo de ensinoaprendizagem e especificamente sobre a deficiência intelectual é também observada em outras pesquisas. Com efeito, na análise feita por Anache e Mitjáns (2007), a partir do banco de dados da CAPES, no período de 1990 a 2006, foram encontrados 122 trabalhos, entre teses e dissertações, que versavam sobre deficiência intelectual. Destes, somente $6 \%$ dos trabalhos abordaram o processo de aprendizagem desse aluno. Em outra investigação, Glat, Antunes, Braun e Machado (2010) verificaram a mesma tendência ao analisarem a produção científica a cerca da deficiência intelectual e do processo de ensino-aprendizagem, na base de dados do SCIELO. Foram revistas 919 produções de um universo de 42 títulos de periódicos das áreas de educação, psicologia e ciências sociais, disponíveis no site do SCIELO até o ano de 2010, e constatou-se que nenhum artigo abordou o processo de ensinoaprendizagem do aluno com deficiência intelectual, especificamente.

Esta tendência contrasta, contudo, com a encontrada no estudo supracitado de Nunes et al. (2003) o qual revelou que, dentre as 555 teses e dissertações defendidas entre 1981 e 1999, nada menos que 200 trataram do tema genericamente denominado de ensino-aprendizagem. Dentre os subtemas tratados nesse acervo figuravam aquisição de linguagem, práticas educativas e desenvolvimento cognitivo, ensino de habilidades artísticas, físicas e esportivas; treinamento de comportamentos e habilidades básicas, psicomotricidade, interação professoraluno e manejo de classe (NUNES et al., 2004).

Aprofundando no conteúdo dos trabalhos apresentados no grupo do GT 15 da Anped, verificamos que seus autores destacaram algumas adequações e inadequações dos procedimentos e recursos de ensino. Jesus (1996), em estudo realizado em classes regulares, relatou a predominância de estratégias de ensino da alfabetização a partir do método silábico e a oferta de exercícios de separação de sílabas e formação de palavra e leitura de pequenos textos pouco pertinentes à realidade de vida do aluno. Como recurso, a cartilha era o expediente nesse contexto. Os procedimentos de ensino de sequenciação numérica, somas, subtrações e formação de números também seguiam o mesmo caminho. A autora destaca ainda inadequações quanto aos procedimentos adotados para qualquer aluno em fase de alfabetização como: explicações longas e pouco objetivas, ausência de movimentação da professora pela sala para atender aos pedidos de ajuda ou observar a execução da atividade. A individualização de ensino se restringia à oferta de exercícios apresentados em folhinhas avulsas que nem 
sempre envolvia o aluno no processo ao qual toda a turma estava submetida. Jesus (1996) conclui que esses procedimentos revelam formas mecânicas de abordar o desenvolvimento dos alunos, impossibilitando processos de aprendizagens significativas, independentemente do método adotado.

Em contraste com o estudo acima relatado, Monteiro (1996) observou, justamente, a relevância de estratégias e procedimentos de ensino que viabilizassem ao aluno a significação dos conceitos novos adquiridos em sala de aula e além dela, a partir de situações e atividades que propusessem o relato de fatos, experiências, narrativas de histórias do seu tempo. De acordo com a autora:

.... as crianças apresentavam a elaboração de conhecimentos através das relações dialógicas, através da mediação das palavras da professora ou do companheiro mais experiente. Naquele contexto a linguagem organizava o pensamento e as ações no espaço discursivo da sala de aula... (p. 12, grifo nosso)

Note-se que as análises sobre as situações de ensino, nos dois estudos anteriorescitados, semostram contrastantes a respeito da eficácia dos procedimentos adotados. Aqui vale uma ponderação a partir de um aspecto que atravessa essa análise: as condições de ensino. No estudo de Jesus (1996), na sala de aula comum composta por 20 alunos, ainda que considerada como relativamente pequena, é notória a falta de preparo do professor, associada ao seu descontentamento em ter o aluno com deficiência em sua sala de aula. Essas variáveis configuram "um quadro de conflitos e dificuldades" para a organização do processo de ensinoaprendizagem dos alunos (JESUS, 1996, p.13). Em contraste, o estudo de Monteiro conduzido em uma classe especial, aponta que a diferença se fez na forma "como os conteúdos eram ensinados". Assim a eficácia dos procedimentos adotados, como a mediação constante da professora e a mediação entre alunos, parece associada à crença da mestra no potencial dos alunos. Ou seja, a forma de atuação da professora possibilitou uma condição de ensino favorável aos seus alunos.

Silva (1997, 1998) apresentou em seus estudos uma ampla análise sobre procedimentos de ensino a partir do paralelo entre os aportes piagetiano e vigotskiniano. Suas análises corroboram os achados que Monteiro (1996) apresenta sobre a validade da mediação como procedimento necessário ao ensino respaldado na perspectiva histórico-social. Sob esse prisma, procedimentos de ensino que incentivem a interação professor/aluno, favorecendo o diálogo, a cooperação, a oferta de pistas, a troca de informações e experiências e a divisão de tarefas necessárias para a produção do conhecimento constituem o fundamento de práticas pedagógicas que promovem o desenvolvimento de todo e qualquer aluno, independentemente da presença ou não da deficiência.

Sob esta mesma abordagem, Ribeiro e Nunes (1999) enfatizaram que as interações professor-aluno desde a educação infantil "constitui o cerne de todo processo educacional, pois dependerá da qualidade das interações a chance de 
NUNES, L. R. O. P.; BRAUN, P.; WALTER, C. C. F.

retirar esse aluno com necessidades educacionais especiais do isolamento que o caracteriza $[\ldots]^{\prime \prime}$ (p. 03).

Dentre os recursos e procedimentos descritos em alguns dos estudos como eficazes destaca-se o jogo ou a atividade lúdica. Silva (1999), ao analisar documentos nacionais que tratam de propostas curriculares e orientações metodológicas, observa que o jogo é apresentado como estratégia de desenvolvimento motor e cognitivo, como modelador de atitudes e como meio para socialização. Embora esteja assim organizado, ora para desenvolver um aspecto, ora outro, Silva considera que a atividade lúdica deveria, outrossim, "subsidiar a organização, implementação e avaliação das práticas que se constituíssem em meios para a aprendizagem do deficiente mental"(p.15). No estudo de 2000, a autora, volta a criticar a forma com que os jogos são usados e organizados nas propostas de ensino. Ao analisar as perspectivas de professores sobre o conceito de adaptação curricular, a autora observou que sob a égide de um psicologismo, considerado por ela como mecanicista e organicista, e com a preocupação em reabilitar o aluno, o professor procede a uma "singularização de conteúdos e a massificação dos considerados passíveis de aprendizagem, com grande predominância das atividades de leitura, escrita, principalmente, através de jogos" (p. 06).

A mera simplificação das ações e de procedimentos de ensino, ricos em formas de acessar e possibilitar a elaboração de processos de aprendizagem pelo aluno - como o jogo - é um fator marcado pelo viés sob o qual o aluno com deficiência intelectual é caracterizado. Afirmativas como ele é lento, não consegue fazer abstrações, tem um atraso mental, apresenta um déficit, que circulam pela escola, acabam por transformar frequentemente o processo de ensino-aprendizagem desse aluno em um processo de conformismos.

Sobre o empobrecimento ou a falta de procedimentos de ensino que favoreçam o desenvolvimento e aprendizagem, Lunardi (2005), em uma análise que transcende a deficiência, lembra o que nem sempre é destacado nos debates sobre a inclusão de alunos com deficiência intelectual: as práticas curriculares da sala de aula são condicionadas por categorias de tempo e de espaço e pelos demais elementos que compõem a cultura escolar. Esta cultura pouco se adéqua a procedimentos de ensino que demandem um tempo maior, espaços diversos e diferenciados, e o uso de recursos que se desprendam do universo do papel, lápis e borracha.

Na pesquisa de intervenção conduzida por Ferri e Hostins (2006), foram analisadas as práticas docentes junto a alunos regulares e com deficiência de escolas regulares e da APAE. A observação dessas práticas foram seguidas de encontros com os professores para apresentação e discussão dos dados coletados e a oferta de sugestões metodológicas que favorecessem os processos cognitivos dos alunos. Com esta proposição, as autoras sublinharam que é necessário que o docente alinhe conhecimentos de didática e de diversas áreas do conhecimento humano para alavancar o processo de elaboração conceitual dos alunos. Três recomendações 
advindas desse estudo são: articulação dos objetivos da aprendizagem com a execução das atividades pedagógicas propostas, planejamento calcado nos registros das observações e análises do desempenho dos alunos e a valorização da diversidade de respostas do aluno às situações de aprendizagem.

No conjunto de estudos analisados até aqui ratifica-se o que Lunardi (2005) afirma em sua análise ao apontar que a pobreza do conteúdo escolar, a centralidade do ensino em detrimento da aprendizagem, a hierarquização dos sujeitos e disciplinas escolares, a fragilidade do trabalho em relação ao conhecimento sobre o ensinar e o aprender, mesmo de capacidades básicas como o ler, escrever e contar, torna a escola carente de procedimentos, recursos e estratégias para todo o alunado, independentemente da presença ou não da deficiência.

As brincadeiras e o faz-de-conta são outros procedimentos apontados como relevantes ao desenvolvimento de propostas pedagógicas para o ensino. Tal consideração, assim como as que apontam o jogo como estratégia e recurso de ensino, está embasada no aporte teórico vigotskiniano. Vale ressaltar que as situações de ensino que utilizam tais procedimentos e recursos, para se configurarem como estratégias de ensino eficazes, precisam estar focalizadas no desenvolvimento do aluno, nas formas de interação do aluno nas diversas situações, em seus mecanismos para lidar, significar, questionar, criar e mudar. Os jogos e as brincadeiras, quando alheios a essa proposição, tornam-se atividades para meramente ocupar o tempo do aluno e não para ensinar.

Os trabalhos de Padilha (1999), Miranda (1999) e Victor (2001) também se alinham nesta perspectiva favorável ao aspecto lúdico. Padilha (1999) nos remete às possibilidades de ensino de uma aluna de 17 anos com significativos comprometimentos intelectuais. Por meio de situações imaginárias como brincadeira de casinha, de loja, de vendedora e de jogos, a pesquisadora observou uma transformação no desenvolvimento simbólico da jovem. Nesse sentido, Padilha se contrapõe à premissa incorporada pelo senso comum sobre as impossibilidades do aluno com déficits cognitivos. Com efeito, a autora propõe que as estratégias e recursos de ensino devem visar "o investimento nos processos de abstração, no lugar de treinamentos motores descontextualizados e repetitivos" (p. 04).

Para Miranda (1999), as atividades lúdicas constituem "estratégias de intervenção pedagógica nos processos cognitivos de alunos deficientes mentais, como meio de criar um espaço para pensar, em que estão presentes os aspectos cognitivos e afetivos, fértil campo de trabalho pedagógico" (p. 01). Victor (2001) acrescenta que a idéia da utilização do jogo, das brincadeiras e do faz-de-conta consiste em observar essas dinâmicas "não somente em seu aspecto didático, mas como atividade mediadora entre o real e a fantasia comum a toda criança" (p.05). Com base no conceito de zona de desenvolvimento proximal, podemos afirmar que na brincadeira compartilhada, o aluno com deficiência aprende com o colega através das ações e das lembranças das mesmas no cotidiano. 
NUNES, L. R. O. P.; BRAUN, P.; WALTER, C. C. F.

Os estudos de Boneti (1997, 1999) e Gomes e Figueiredo (2003) partiram fundamentalmente de dois pressupostos: a) a aquisição da escrita e da leitura pela criança decorre de sua evolução cognitiva e psicolinguística e não de suas habilidades perceptuais e visomotoras e b) na aquisição de ambas as habilidades, a criança com deficiência intelectual exibe processos cognitivos e estratégias semelhantes aos da criança com desenvolvimento típico. Assim, no estudo sobre língua escrita, utilizando uma metodologia interativa desenvolvida por Ferreiro e Teberosky (1986), assentada no método clinico de Piaget, o experimentador fazia proposições à criança referentes a cartões com diferentes amostras de escrita com o propósito de descobrir as hipóteses formuladas por ela e a lógica de seu raciocínio. Ao estudar a construção do significado da leitura por alunos com deficiência, Gomes e Figueiredo (2003) concluíram que a mediação pedagógica, realizada através da apresentação de situações-problema e formulação de perguntas, promovia intencionalmente conflitos e desafios cognitivos no aprendiz, para favorecer a emergência de estratégias cognitivas e metacognitivas, elementos críticos para este aprendizado.

Sintetizando as contribuições dos diversos estudos revisados, merece destaque a conclusão de Silva (1997) de que é a baixa qualidade dos procedimentos pedagógicos destinados à população com deficiência que esse alunado acaba por exibir níveis inferiores em seu processo de escolarização. Com efeito, as possibilidades de aprendizagem, assim como os recursos e procedimentos usados para esta população ainda são pensados pelo viés do déficit. Muitas das atividades analisadas e seus procedimentos revelaram a pouca preocupação com os processos de aprendizagem e de elaboração cognitiva do aluno, e a ênfase sobre o produto final - aprendeu ou não aprendeu.

Acreditamos que quando os professores focalizam sua atenção ao momento da realização da atividade pela criança ou jovem, à sua forma de pensar e agir em resposta a uma proposta pedagógica, eles se deparam com a possibilidade de conhecer como o aluno pode aprender. Assim, o educador tem a oportunidade de analisar a adequação do procedimento pedagógico ou recurso empregados, os quais só se mostram efetivos quando favorecem a aprendizagem. Talvez a inadequação de determinados procedimentos e recursos, constatada em alguns dos estudos apresentados, tenha assim se configurado por conta desta carência de olhar sobre o processo. Pensar um recurso ou procedimento de ensino exige conhecer as formas de aprendizagem do aluno a quem pretendemos educar.

\section{Trabalhos SObre alunOS SURdos}

Os 12 estudos que trazem como população-alvo alunos com surdez tiveram seus pressupostos teóricos alicerçados em Vygotsky, Bakhtin e Skliar. Essas investigações focalizaram as mudanças na prática pedagógica em sala de aula em busca de soluções para as dificuldades de comunicação e do processo de alfabetização de alunos surdos. 
Vale ressaltar que ao analisar os estudos que tratam do uso da Língua Brasileira de Sinais (LIBRAS) pelos alunos com surdez, ficam evidenciadas as mudanças ocorridas nas últimas décadas, desde a tradição oralista, passando pelo modelo da comunicação total até o atual paradigma do bilinguismo que reforça a legitimidade da LIBRAS como língua materna do individuo com surdez e estimula o domínio do Português como segunda língua. Com efeito, a utilização da LIBRAS ganhou maior destaque nos últimos anos, respaldada em documentos oficiais que nortearam a política de inclusão escolar dos alunos com deficiência. Em 2002, foi promulgada a Lei $n^{\circ}$. 10.436/02 que reconhece a Língua Brasileira de Sinais (LIBRAS) como meio legal de comunicação e expressão das pessoas surdas no Brasil. Não obstante a lei, as pesquisas continuavam buscando discutir e responder questões relacionadas aos procedimentos e técnicas de ensino que proporcionassem melhor desempenho nas atividades envolvendo a constituição da linguagem escrita e alternativas de letramento para o aluno surdo.

Os estudos conduzidos por Freitas (1996), Gesueli e Goes (1998), Gesueli (1999), Lacerda (2000) e Oliveira (2001) descrevem e analisam tanto o processo de aquisição de linguagem como os procedimentos e técnicas de alfabetização, de leitura e de escrita conduzidas em sala de aula por alunos surdos. Os autores foram unânimes em defender o uso da LIBRAS como primeira língua do individuo surdo, considerada como um complexo sistema de signos, indispensável ao desenvolvimento da cognição e da interação social e que permite o desempenho de atividades acadêmicas e sociais na escola.

Estes e os demais estudos sobre escrita e leitura revisados aqui mostraram ainda que: a) a apresentação do conteúdo da escrita por meio de LIBRAS, acompanhada de figuras ilustrativas afeta positivamente a performance da escrita, da compreensão e da interpretação de texto por alunos surdos (GESUELI; GÓES, 1998; GESUELI, 1999), b) o aluno inserido no paradigma do bilinguismo, comparativamente `aqueles educados nas tradições oralista e da comunicação total, demonstra melhor organização do pensamento e compreensão de conceitos, mesmo havendo grandes diferenças entre a estrutura gramatical da LIBRAS e da Língua Portuguesa (OLIVEIRA, 2001), c) a surdez não é empecilho para a aprendizagem da linguagem escrita, a partir do momento que sejam utilizadas práticas de escrita mais dialógicas, mais interativas e menos mecânicas (OLIVEIRA, 2003), d) o uso da língua de sinais é fator determinante para a compreensão de textos pelas pessoas surdas e sua aquisição prévia ao contato com textos e narrativas escritas favorece sobremaneira o domínio da Língua Portuguesa (LEBEDEFF, 2003), preconizandose assim a presença de professores surdos ou ouvintes bilíngues que possam auxiliar os alunos surdos no processo de letramento (LEBEDEFF, 2005).

Na busca de contextualização das práticas de letramento das comunidades surdas no Brasil, Casarin (2005) selecionou livros e contos conhecidos da literatura portuguesa e produziu 12 livros impressos com o auxílio da computação gráfica que recontavam as histórias utilizando imagens de sinais, filmagens das cenas em LIBRAS, imagens sinalizadas, alfabeto digital e símbolos direcionais. A produção 
NUNES, L. R. O. P.; BRAUN, P.; WALTER, C. C. F.

desse material literário em LIBRAS e em Língua Portuguesa constitui mais uma tentativa de ampliar as possibilidades de acesso dos surdos ao mundo letrado.

Dois estudos se debruçaram sobre programas de ensino de LIBRAS destinados a famílias ouvintes de alunos surdos. Em seu trabalho, Lebedeff (2007) descreveu um programa de leitura compartilhada ${ }^{6}$ desenvolvido nos Estados Unidos cujo objetivo principal era ensinar as famílias a ler livros em língua americana de sinais, utilizando estratégias surdas. A autora participou da capacitação na utilização do Programa e concluiu que o projeto requer ajustes para a cultura brasileira e que a leitura compartilhada precoce propicia a aquisição da leitura e da escrita por crianças surdas, promove o estreitamento das relações familiares, a melhoria da comunicação entre as crianças surdas e seus pais e a ampliação das atividades de letramento para as famílias. A investigação de Dias, Pedroso e Rocha (2003) corroborou tais achados ao destacar a importância da mediação realizada por instrutores surdos no ensino de estratégias aos familiares ouvintes de surdos, favorecendo assim interações mais lúdicas e prazerosas com seus filhos surdos.

As pesquisas envolvendo participantes surdos tiveram destaque até o período 2001- 2005 e a partir desta data outras populações passaram a ser igualmente estudadas. Todavia, nos últimos anos, o processo de inclusão escolar de alunos com deficiência nas escolas regulares dominou todo o cenário da pesquisa sobre alunos com deficiência. Segundo esta tendência, Rodrigues (2010) investigou por meio da observação da dinâmica de funcionamento da sala de aula do ensino regular, como alunos surdos, usuários da LIBRAS e professores ouvintes, competentes em Língua Portuguesa, vivenciam situações do cotidiano da sala de aula e em especial a situação do bilinguismo. $O$ resultado descrito remete à importância de organização estrutural da sala de aula, desde questões espaciais, uma vez que estas promovem os padrões interacionais entres os alunos e professor. Segundo o autor, o professor é desafiado a ampliar o uso de recursos e estratégias didáticas, os meios de comunicação e os recursos visuais, capazes de possibilitar a construção de um entendimento comum de todos os aspectos envolvidos no processo de ensino-aprendizagem.

\section{TrABALHOS SOBRE ALUNOS COM DEFICIÊNCIA MÚLTIPLA}

Ainda que relativamente pouco numerosos, observa-se tendência levemente ascendente, a partir dos anos 2000 na produção de estudos com crianças com deficiência visual, deficiência múltipla e deficiência motora, alavancada pelas práticas de inserção de alunos com deficiência nas escolas regulares. Outro aspecto importante refere-se ao aumento de pesquisas de cunho quantitativo que passaram a demonstrar experimentalmente a eficiência e a eficácia de técnicas, estratégias e adaptações curriculares e, assim, atender às necessidades dos professores que

${ }_{6}^{6}$ Shared Reading Program ( SCHLEPER, FERNANDES; HIGA, 1993) 
atuam em salas de aula, com alunos incluídos ou no Atendimento Educacional Especializado (AEE).

Costa e Cader-Nascimento (2005) desenvolveram uma pesquisa de intervenção em sala de aula com o objetivo de criar novas competências e desenvolver novos repertórios de comportamento de leitura e escrita em duas crianças surdocegas pré-linguísticas, envolvendo a aprendizagem de diferentes recursos de comunicação. No estudo, desenvolvido em escola pública, foi proposto o ensino de leitura e escrita utilizando atividades adaptadas avaliadas nas fases inicial e final. Os resultados demonstraram melhora na realização das atividades por meio do uso da comunicação alternativa, assim como nos aspectos motricionais da fala e no desempenho de atividades de vida diária. A fundamentação teórica nos estudos de Chomsky permitiu análise aprofundada nas questões de aquisição de linguagem. Com efeito, as participantes passaram a demonstrar maior intenção comunicativa e utilização de gestos e outros sinais como formas alternativas de comunicação. Tais ganhos repercutiram positivamente no ambiente familiar, promovendo novos padrões de interação.

Com o compromisso de descrever as possibilidades de intervenção pedagógica de crianças surdas com baixa visão, Cader e Costa (2000) se propuseram a ampliar os meios de comunicação desses alunos através da aquisição das letras do alfabeto associada à datilologia na identificação de atividades e situações de sala de aula. Os dados revelaram que os alunos passaram a reconhecer o próprio nome e os dos colegas a partir do uso de letras destacadas em relevo associadas a um sinal estabelecido. Foi observada igualmente a superação das dificuldades de locomoção.

Bruno (2007) propôs uma avaliação educacional para alunos inseridos na educação infantil com baixa visão e deficiência múltipla. A proposta da autora era adaptar instrumentos para estudar as funções visuais nos processos de desenvolvimento e de aprendizagem na educação infantil e a partir daí elaborar instrumentos de avaliação pedagógica que detectassem habilidades funcionais, competências e necessidades especiais especificas. Os pressupostos teóricos estavam assentados nas teorias construtivista de Piaget e sociohistórica de Vygostsky, enfatizando as relações sociais e a interação homem-objeto, mediada por sistemas simbólicos. Os resultados apontaram para melhoria significativa no desempenho global das crianças. Procedimentos de mediação e ajuda para compensação das dificuldades da criança com baixa visão e outros comprometimentos foram propostos. Alem disso, foi mostrado que a organização do ambiente e a adaptação dos recursos materiais se constituíram em elementos decisivos e incontestáveis para o êxito nas atividades realizadas pelos professores.

\section{Trabalhos SObre alunOS COM DEFICIÊNCIA VISUAL}

Um estudo apresentado por Cunha, Enumo e Dias (2009), apoiado no paradigma da aprendizagem mediada (EAM) proposta por Feuerstein (2001), 
NUNES, L. R. O. P.; BRAUN, P.; WALTER, C. C. F.

envolveu 34 alunos com deficiência visual e dificuldades de aprendizagem e investigou indicadores cognitivos e comportamentais em situação de avaliação cognitiva em provas assistidas. Os dados evidenciaram benefícios em relação ao desempenho quando utilizadas estratégias cognitivas eficientes providas pela mediação, principalmente em situações envolvendo atividades lúdicas.

Uma análise documental realizada por Seabra Junior (2009) focalizou as adaptações de estratégias de ensino e recursos pedagógicos destinados às atividades físicas de alunos com deficiência visual. Ficou evidenciada a importância da descrição de material e equipamentos adequados ou adaptados para facilitar o desempenho de atividades físicas, esportivas, de lazer e/ou desenvolvimento da independência nas atividades de vida diária de pessoas cegas ou com baixa visão.

\section{Trabalhos SObRe ALUNOS COM DEFICIÊNCIA FÍSICA}

Associada à discussão de um espaço de ensino com estratégias de trabalho coletivo, com a mediação constante do professor e o uso de recursos que se afastam do convencional da escola, Lopes (2005) descreveu uma investigação desenvolvida no espaço de uma oficina de fotografia para alunos com paralisia cerebral envolvidos. Segundo a pesquisadora, a dinâmica se caracterizou como um lugar de interlocução onde a linguagem fotográfica foi o principal viés de mediação dos processos de construção do conhecimento, de constituição de subjetividades, de interação social e de produção artística.

Dois trabalhos demonstraram o crescente interesse dos pesquisadores pelo desenvolvimento de estratégias adaptadas às necessidades de alunos com paralisia cerebral inseridos em salas especiais e também para adultos moradores de centros especializados, fundamentadas nos pressupostos teóricos de Vygostsky Leontiev e Piaget. O estudo proposto por Braccialli, Manzini e Regahan (2004) verificou a contribuição de um programa de 17 jogos e brincadeiras adaptadas para o desenvolvimento de alunos com deficiência física que, por meio de filmagens, pode identificar variáveis importantes sobre a contribuição das atividades no desenvolvimento global dos alunos. A contribuição dos estudos nessa área trouxe mudanças significativas no processo educacional de alunos com dificuldades motoras, onde o acesso e mobilidade estão comprometidos pelas dificuldades de autonomia e comunicação presentes em pessoas com paralisia cerebral.

Um projeto pedagógico em ambiente computacional e telemático foi desenvolvido por Galvão Filho (2005) que conduziu um estudo de caso envolvendo quatro jovens com paralisia cerebral fazendo uso das Tecnologias de Informação e Comunicação (TICs), como o uso da internet, e-mail e construção de home page. A meta da investigação era favorecer a inclusão social e progressos na aprendizagem e na interação social desta população, segundo dos pressupostos teóricos a presentados por Vygotsky, Piaget e Paulo Freire. Os resultados apontaram para um crescimento da motivação e da autoestima dos alunos, corroborando 
Procedimentos e recursos de ensino

na aprendizagem da leitura e da escrita, na construção de novas interações, promovendo assim a inclusão social da pessoa com paralisia cerebral.

\section{CONCLUSÕES}

Os estudos aqui revisados são eloquentes em destacar a relevância da mediação no processo de aprendizagem de qualquer aluno, sobretudo daquele com deficiência. Com efeito, compreender o processo de mediação a partir do uso de instrumentos e de signos, como uma característica da relação entre indivíduos e deles com o mundo é essencial, pois é a partir desse processo que as funções psicológicas superiores desenvolvem-se (BRAUN, 2011). Mediação é um recurso fundamental para garantir a "qualidade das experiências sociais e culturais da criança, e de capital importância para compensar as limitações funcionais que as crianças com deficiência enfrentam, já que a priori encontram limitações na linha orgânica ou biológica do desenvolvimento" (BEYER, 2005, p. 05). De fato, o processo de desenvolvimento do aluno com deficiência não ocorre da mesma forma que do aluno sem deficiência, não pela condição de deficiência exatamente, mas porque o olhar do outro nem sempre lhe confere a possibilidade para aprender e se desenvolver. Nos meandros sociais vigentes a tendência ainda é a de reduzir as pessoas com deficiência à sua condição orgânico-estática.

Deste modo, é preciso que o professor do aluno com deficiência tenha como lema que o bom ensino é aquele se adianta ao desenvolvimento e o conduz à frente (VYGOTSKY, 2008). Assim,

\footnotetext{
... constatar o que já é efetivo na aprendizagem da criança é parte do processo de ensino, mas não se encerra aí. Na verdade, é ponto de partida para novas situações que precisam ser instigadas, mediadas a favor de novas aprendizagens que conduzam a níveis de desenvolvimento que estão por ser organizados pelo aluno (BRAUN, 2011, p.81).
}

\section{REFERÊNCIAS}

ANACHE, A. A.; MITJÁNS, A. M. Deficiência mental e produção científica na base de dados da CAPES: o lugar da aprendizagem. Revista Brasileira de Psicologia Escolar e Educacional, v.2, n. 2, p. 253-273, 2007.

BEYER, H. Inclusão e avaliação na escola de alunos com necessidades educacionais especiais. Porto Alegre: Mediação, 2005.

BONETI, R. V. F. O texto para ler, o desenho para olhar: a interpretação da criança com deficiência mental. In: REUNIÃO ANUAL DA ANPED, 22., 1999. Anais... 1999.

. A interpretação da escrita pela criança portadora de deficiência intelectual. In: REUNIÃO ANUAL DA ANPED, 20., 1997. Anais... 1997. 
NUNES, L. R. O. P.; BRAUN, P.; WALTER, C. C. F.

BRACCIALLI, L. M. P.; MANZINI, E. J.; REGANHAN, W. G.; Contribuição de um programa de jogos e brincadeiras adaptados para a estimulação de habilidades motoras em alunos com deficiência física. In: REUNIẪO ANUAL DA ANPED, 27., 2004. Anais... 2004.

BRAUN, P. A inclusão de alunos com deficiência intelectual no ensino fundamental de uma escola pública. 2011. Texto de exame de qualificação ao doutorado. Programa de Pós- Graduação em Educação da Universidade do Estado do Rio de Janeiro. 2011.

BRUNO, M. M. G. Avaliação educacional para alunos com baixa visão e múltipla deficiência na educação infantil: uma proposta de adaptação e elaboração de instrumentos. In: REUNIÃO ANUAL DA ANPED, 30., 2007. Anais... 2007.

CADER, F. A. A. A.; COSTA, M. P. R. Possibilidades de intervenção pedagógica de crianças surdas com baixa visão. In: REUNIÃO ANUAL DA ANPED, 23., 2000. Anais... 2000.

CASARIN, M. M. Produção de livros bilíngues: língua de sinais e língua portuguesa. In: REUNIÃO ANUAL DA ANPED, 28., 2005. Anais... 2005.

COSTA, M. P. R. O ensino da iniciação à matemática para alunos deficientes mentais estudo I: agrupamento por semelhança perceptiva absoluta. In: REUNIÃO ANUAL DA ANPED, 22., 1999. Anais... 1999.

COSTA, M. P. R.; CADER, F. A. A. A. O ensino da leitura e escrita para estudantes surdocegas. In: REUNIÃO ANUAL DA ANPED, 28., 2005. Anais... 2005.

CUNHA, A. C. B.; ENUMO, S. R. F.; DIAS, T. L. Análise de indicadores cognitivos e comportamentais em provas assistidas com crianças com necessidades educativas especiais. In: REUNIÃO ANUAL DA ANPED, 22., 1999. Anais... 1999.

DIAS, T.; PEDROSO, C.; ROCHA, J. Uma análise sobre o ensino de libras e familiares ouvintes de alunos surdos. In: REUNIÃO ANUAL DA ANPED, 26., 2003. Anais... 2003.

FERRI, C.; HOSTINS, R. C. L. Currículo e diferença: processos de seleção e organização de conhecimentos para atendimento educacional de alunos com histórico de deficiência mental. In: REUNIÃO ANUAL DA ANPED, 29., 2006. Anais... 2006.

FREITAS, T. A. Desenvolvimento da linguagem: diferentes perspectivas de um tema vygotskiano. In: REUNIÃO ANUAL DA ANPED, 19., 1996. Anais... 1996.

GALVÃO FILHO, T. A. O desenvolvimento de projetos pedagógicos em ambiente computacional e telemático com alunos com paralisia cerebral. In: REUNIÃO ANUAL DA ANPED, 28., 2005. Anais... 2005.

GLAT, R. et al. Uma análise da produção científica sobre deficiência intelectual na base de dados SCIELO: o processo de ensino-aprendizagem em foco. In: CONGRESSO BRASILEIRO DE EDUCAÇÃO ESPECIAL, 6., 2010, São Carlos. Anais... São Carlos: UFSCar, 2010.GE

GESUELI, Z. M. A língua de sinais na elaboração da criança surda sobre a narrativa. In: REUNIÃO ANUAL DA ANPED, 22., 1999. Anais... 1999.

GESUELI, Z. M.; GÓES, M. C. R. A língua de sinais na elaboração da criança surda sobre a escrita. In: REUNIÃO ANUAL DA ANPED, 21., 1998. Anais... 1998. 
Procedimentos e recursos de ensino

GOMES, A. L.; FIGUEIREDO, R. V. A emergência das estratégias de leitura em sujeitos com deficiência mental. In: REUNIÃO ANUAL DA ANPED, 26., 2003. Anais... 2003.

JESUS, D. M. Redescobrindo a sala de aula: o portador de necessidades educativas especiais na classe regular. In: REUNIÃO ANUAL DA ANPED, 19., 1996. Anais... 1996.

LACERDA, C. B. F. A inserção da criança surda em classe de crianças ouvintes: focalizando a organização do trabalho pedagógico. In: REUNIÃO ANUAL DA ANPED, 23., 2000. Anais... 2000.

LEBEDEFF, T.B. Análise da compreensão textual de surdos adultos de textos em línguas de sinais e escritos. In: REUNIÃO ANUAL DA ANPED, 26., 2003. Anais... 2003.

LEBEDEFF, T.B. Análise das estratégias e recursos "surdos" utilizados por uma professora surda para o ensino de língua escrita. In: REUNIÃO ANUAL DA ANPED, 28., 2005. Anais... 2005.

. Alternativas de letramento para crianças surdas: uma discussão sobre o shared reading program. In: REUNIÃO ANUAL DA ANPED, 30., 2007. Anais... 2007.

LUNARDI, G. M. As práticas curriculares de sala de aula e a constituição das diferenças dos alunos no processo de ensino e aprendizagem. In: REUNIÃO ANUAL DA ANPED, 28., 2005. Anais... 2005.

LOPES, A. E. Ato fotográfico e processos de inclusão: análise dos resultados de uma pesquisa-intervenção. In: REUNIÃO ANUAL DA ANPED, 28., 2005. Anais... 2005.

MIRANDA, T. G. Caminhos para construção do conhecimento e da subjetividade com alunos portadores de necessidades especiais. In: REUNIÃO ANUAL DA ANPED, 22., 1999. Anais... 1999.

MONTEIRO, M. S. Nas relações dialógicas: o cotidiano de uma classe especial. In: REUNIÃO ANUAL DA ANPED, 19., 1996. Anais... 1996.

NUNES, 1. R.; FERREIRA, J. R.; MENDES, E.G. Análise crítica das teses e dissertações nas áreas de Educação e Psicologia: o estado da arte do conhecimento sobre a educação do portador de necessidades educacionais especiais. Relatório final de pesquisa aprovado pelo $\mathrm{CNPq}$ (proc. 524226/96-2), 2003.

NUNES, 1. R. et al. O que revelam as teses e dissertações sobre linguagem e comunicação de pessoas com necessidades especiais. Temas em Psicologia, Ribeirão Preto, v. 10, n. 1, p. 27-38, 2004.

OLIVEIRA, L. A. A escrita do surdo: relação texto e concepção. In: REUNIÃO ANUAL DA ANPED, 21., 2001. Anais... 2001.

OLIVEIRA, L. A. A construção da linguagem escrita do aluno surdo, na escola regular, à luz da perspectiva sócio-histórica. In: REUNIÃO ANUAL DA ANPED, 26., 2003. Anais... 2003.

PADILHA, A. M. L. Constituição do processo de simbolização: uma proposta pedagógica destinada aos deficientes mentais a partir da contribuição da perspectiva históricocultural do desenvolvimento humano. In: REUNIÃO ANUAL DA ANPED, 22., 1999. Anais... 1999. 
NUNES, L. R. O. P.; BRAUN, P.; WALTER, C. C. F.

RIBEIRO, A. M.; NUNES, L. R. O educador de creche como provedor de condições para a integração de crianças com necessidades especiais em ambiente de creche. In: REUNIÃO ANUAL DA ANPED, 22., 1999. Anais... 1999.

RODRIGUES, C. H. Diferença linguística e cultural na perspectiva da inclusão: padrões interacionais e aprendizagem na sala de aula de surdos. In: REUNIÃO ANUAL DA ANPED, 33., 2010. Anais... 2010.

SEABRA JUNIOR, M. O. Estratégias de ensino e recursos pedagógicos para o ensino do aluno com deficiência visual na atividade física adaptada. In: REUNIÃO ANUAL DA ANPED, 32., 2009. Anais... 2009.

SILVA, F. C.T. Procedimentos didáticos especiais no ensino do deficiente mental: um caminho de interlocução. In: REUNIÃO ANUAL DA ANPED, 20., 1997. Anais...1997.

. Desenvolvimento e aprendizagem: deficiência mental sob a ótica das teorias cognitivas. In: REUNIÃO ANUAL DA ANPED, 21., 1998. Anais... 1998.

. Jogo: procedimento didático especial no ensino do deficiente mental. In: REUNIÃO ANUAL DA ANPED, 22., 1999. Anais... 1999.

. Processos de ensino da educação dos deficientes mentais. In: REUNIÃO ANUAL DA ANPED, 23., 2000. Anais... 2000.

VICTOR, S. L. Aspectos presentes na brincadeira de faz-de-conta da criança Síndrome de Down. In: REUNIÃO ANUAL DA ANPED, 24., 2001. Anais... 2001.

VIGOTSKY, L. Pensamento e linguagem. 4. ed. São Paulo: Martins Fontes, 2008.

Recebido em: 04/08/2011

Aceito em: 30/08/2011 